\title{
On the possibility of organ markets and the performativity
}

\section{of economics}

\author{
Philip Roscoe \\ School of Management \\ University of St Andrews \\ The Gateway, North Haugh \\ St Andrews, Fife, KY16 9RJ
}

Tel: 01334461973

pjr10@st-andrews.ac.uk 


\section{Abstract}

Callon's (1998) 'performativity thesis' encourages us to consider how the boundaries of the economy are negotiated. This paper explores one such discussion: the contributions of economics to the debates over the introduction of markets for transplant organs. The paper pays particular attention to the normative aspects of economic valuation. It examines the philosophical antecedents of economic contributions to the debate, notes the rhetorical and linguistic power of economic calculation and then focuses on three distinct sets of calculations concerning the value of a transplant kidney: a contingent valuation calculation, a risk-premia based calculation, and a cost-efficiency simulation. In each case, it shows that economic facts, once created, may travel freely through normative debates and claim moral force. The technical process of economic modelling is therefore seen to be a crucial aspect of the economisation of this area, and of economic performativity more generally.

\section{Keywords}

'performativity', 'organ markets', 'bioethics', 'transplant organs', 'valuation', 'contingent valuation method' 


\section{Introduction: economising organs}

The growing literature of 'performativity' (Callon, 1998) argues that the economy is a socially negotiated and bounded arena, and that it is 'embedded' in economics, a discipline with distinct historical and political objectives (Cochoy, Giraudeau \& McFall, 2010). How, then, are the boundaries of the economic negotiated? While the adoption of economic valuation within hitherto 'social' spaces has been studied at length by, for example, Viviana Zelizer $(1979 ; 2005)$, such studies have concentrated on the organisational and cultural work involved in the process of economisation, and have tended to ignore the technicalities of valuation. Work on more technical aspects of valuation (Çalışkan \& Callon, 2009:389) has focused the construction of economic agents and institutions, rather than the battles between competing realms of value. Empirical studies of valuation have either focused on areas that are self-evidently economic - for example MacKenzie's (2006) study of the performative nature of options pricing theory - or have been content to recognise that an economic mode of valuation has been imposed as part of a political project - for example, Holm's (2007) account of the economisation of the fishing industry. The present paper bridges that gap by considering the role of technical economic valuation in the highly contested economisation of one particular area: the procurement of organs for transplantation. It examines the ability of economics to appropriate, on the basis of technical expertise and its attendant moral claims, contested or ethically fraught aspects of social life. The paper pays particular attention to the rhetorical power of economic reasoning (McCloskey, 1986), and to the linguistic aspects of performativity (Ferraro, Pfeffer \& Sutton, 2005); it offers a complement to the devices-andorganisation account of economic performativity in organ transplantation offered by Steiner (2010). In concentrating on the linguistic and rhetorical aspects of economic performativity, particularly in the context of boundary-setting, it is also possible to draw parallels between 
the performativity research programme and cultural studies of economization (Zelizer, 1979; Zelizer, 2005).

This paper argues that the boundary of the economic is negotiated through border skirmishes: fiercely contested linguistic and calculative interventions, laboratory experiments to determine the 'natural prices' that might exist in the wild and their likely consequences (Tryggestad, 2005). These interventions have power enough to transform the world around them from the fulcrum of the laboratory (Latour, 1988) and are therefore an important topic for scrutiny. I follow the methodological injunction of the performativity program in investigating how such discussions are embedded in the everyday activities of economics, here calculations, surveys and simulations. I examine the arguments concerning the introduction of markets for the procurement of transplant organs, many of which took place in medical and economic journals throughout the late 1990s and early part of the following decade. I explore a series of interventions from academic economists seeking to argue, on economic grounds, for the moral permissibility, the practical cogency, and the organisational superiority of market-based systems. The paper will show that technical, economic 'facts' come to have moral force and figure large in the debate between contesting regimes of valuation. These facts - numbers and prices - are created through models and simulations and subsequently travel through arguments of differing kinds. Freed from their history, they recast 'moral' discussions terms of efficiency and best price. The use of incentives for organ procurement remains for the moment illegal, and the models stay firmly in the laboratory. Even there, the models and techniques of economic theory are deeply performative, asserting the basic axioms of instrumental, utility-maximising rationality. 
The paper will begin by setting out the theoretical claims of the performativity thesis in more detail and considering the normative content of applied economic analysis, suggesting that economics is able to argue 'ought' from 'might be': that calculations have their own moral force. I develop this argument by reviewing in detail three sets of economic calculation of the value of a transplant kidney: a contingent valuation calculation, a calculation based on risk premia and the statistical value of life, and a cost-efficiency simulation. In each case I show that economic facts are constructed, claim moral force, and come to dominate a discussion previously had in philosophical terms. The article then discusses and concludes, offering suggestions for future research.

\section{Ought from might be: the moral performativity of economics}

The performativity thesis (Callon, 1998), said to be 'the most challenging recent theoretical contribution to economic sociology' (MacKenzie \& Millo, 2003:107), represents the claim that economics is a socially constitutive theory with the moral and technical authority to organise the world in particular ways. Economic valuation 'performs, shapes and formats' (Callon, 1998:2) institutions and organizations. Sustained by repeated use of economic practices, valuations and calculations, they are the 'summing up of interactions through various kinds of devices, inscriptions, forms and formulae' (Latour, 1999a: 17). Material entities instantiate economic theory in organizational settings without transforming the 'economic representations or beliefs' of those involved (Steiner, 2010:249). In the field of organ transplantation, for example, Steiner is able to show that the introduction of organswapping mechanisms built upon notions of gift-giving (Roth, Sönmez \& Ünver, 2005) 'performs' surgeons' activities without their direct cognizance of the complex relations of gift-exchange. 
Despite an emphasis on the material aspects of market arrangements, the linguistic component of performativity also remains important (Licoppe, 2010). Economics provides a technical vocabulary that can compete with other social or moral discourses for claims on the organization of social structures (McCloskey, 1986), disentangling and framing calculative activity (Callon, 1998; Ferraro, Pfeffer \& Sutton, 2005). ${ }^{1}$ Debates over economising organ transplants are based on facts, and, as Latour (1999b) shows, facts have a career and a history. Created as locally valid artefacts in specific settings, they are universalised as facts, and enrolled in subsequent advances and debates; 'the career of a fact tends to make the history of its production vanish' (MacKenzie, 2009: 9). Economic facts are created by modelling, and while this is often unstable and contested, the offspring of the models cut loose from their origins and travel, unquestioned, into subsequent models and debates. In particular, as this paper will show, economic facts may be deployed in debates that have not previously been economic in nature, entering the preserve of moral theorists and radically changing the nature of the debate. It is the ability to reframe the debate thus, to recast the terms of argument into economic measures, to discard some goods and emphasise others, that makes the language of economics performative.

To some extent, the ground has already been prepared for the incursion. Economics, with its focus on individual choice, shares an intellectual heritage with contemporary bioethics. Gerald Dworkin (1994:155) makes autonomy the basis for an elegant and robust defence of organ sales. In accepting the legitimacy of organ sales, he argues, we recognise the autonomy of individuals, their sovereignty and ownership of their body parts, and their right to make choices about how others treat their body. The right to choose forms the basis of the arguments in defence of organ markets offered by the philosophers James Taylor (2005) and

\footnotetext{
${ }^{1}$ The notion of performativity itself owes a debt to philosopher of language JL Austin (1978)
} 
Mark Cherry (2005) who are prepared to defend markets against charges of exploitation through poverty (Scheper-Hughes, 2003): 'Removing what the poor may see as an attractive option, so as to assuage feelings of repugnance on the part of the affluent, itself coercively limits the liberty of the poor autonomously to assess available opportunities to better their lives' (Cherry, 2005:84).

Autonomist arguments shade easily into economic commentaries. It is possible, for example, to talk of an impoverished individual turning physical capital (organs) into a more productive human capital by selling an organ and spending the funds on education (Barnett, Saliba \& Walker, 2001:379). Cherry's language, too, is unashamedly that of neo-classical economics: 'If an organ market would best utilize the available organ resources, or would best maximize benefits for persons, these factors would be sufficient to make a market morally acceptable...' (Cherry, 2005: 70). The test, as he admits, is how we should calculate benefits, and he is full of suggestions of what the market, as a space of possibility, might do: markets would allow the purchase of organs for the poor (ibid: 102); church fundraisers would sell their own organs for charity (ibid: 78); a poor man may consider organ sale an honourable and positive solution to financial problems (ibid: 84). Supporters of the market assert that it generates its own ethical standards, laws of ownership and stable relationships; the common intellectual ancestry of autonomist moral philosophy and neoliberal economics allows the narrative of one to segue neatly into the other. Moreover, the allocation of scarce resources is a core disciplinary interest for economics. Papers invariably begin with a statement of the scarcity of transplant organs, illustrating this with a comparison of waiting list figures versus the actual number of transplants performed, or organs available. The very existence of scarcity seems to be enough, in itself, to legitimize economic intrusion into a debate that otherwise concerns medical practitioners and moral philosophers (Roth, 2007). In other 
instances, such as the construction of non-monetary clearing houses for transplant organs (Roth, Sönmez \& Ünver, 2005) economists may perceive that their special skills may be of service to the medical community.

It is equally likely, however, that economics colonizes the topic out of a sense of disciplinary superiority, just as it has aggressively engaged with other ethically charged, non-market issues. Becker (1973) established a framework for analysing marriage as a market, offering a justification for the work derived from the approach of Milton Friedman's 'positive economics' (Friedman, 1966). Becker introduces the topic as a clear act of imperialism, another step in economics' journey towards producing 'a unified framework for all behaviour involving scarce resources, nonmarket as well as market, nonmonetary as well as monetary, small group as well as competitive' (1973: 814). Successful analysis of the marriage market presented 'compelling additional evidence on the unifying power of economic analysis' (p. $814)$; in the best tradition of imperialism, the virtues of colonization are demonstrated through action. The subjugated natives of sociology and philosophy will see the virtue of economics' disciplinary incursion, clearly and in retrospect.

Yet the concept of performativity reminds us that the analysis offered by economists is not devoid of normative content. The description of a social process as a market performs it (in a strictly Austinian sense) as a market. Demonstrating that a functioning market might have certain beneficial effects in principle carries a strongly normative claim that such a market should be enacted in practice. Economic analysis moves seamlessly into social commentary. In fact, as I will show, the economic literature on markets for transplants is rich explicitly normative content. The debate hinges on a substitution of technical expertise for moral competencies; as Alvin Roth remarks, 'it does seem true that when confronted with 
repugnance towards a market transaction, economists often respond as if a sufficiently clear argument focused on the welfare gains due to trade will overcome that repugnance' (Roth, 2007: 49). Economics does indeed deduce 'ought' from 'might be', and so the endeavour of economic theory must be to demonstrate that 'might be' might indeed be: that a market could and would function. The complex set of moral questions surrounding organ markets has become explicitly empirical: let the modelling commence!

\section{Making an economic fact: the price of an organ}

In order to show that markets will function in a socially useful manner, economists must model supply and demand or attempt to arrive at hypothetical prices by other means. In particular, to deal with standard policy objections, economists must show that the use of incentives will not 'crowd out' altruistic donations, and that appropriate prices will generate sufficient demand to have some social impact (Adams, Barnett \& Kaserman, 1999). The economic literature on organ markets offers a variety of strategies in pursuit of these prices, and in this section I will review three such. In each case we can witness the career of the fact (Latour, 1999b): the modelling which results in a price; the severance of that price from the often questionable and arbitrary circumstances of its birth; and the utilisation of the fact as it travels into other models, discussions, and arguments. In each case it is possible to determine the process that Tryggestad (2005) terms 'purification', the expunging of unstable, noneconomic factors (here moral and social concerns) to establish a 'natural' price. As Tryggestad notes, the natural price has enormous power and is capable of rendering other market actors into 'docile servants' (Tryggestad, 2005:603), and something of this kind is discernible in the arguments discussed below. 
The first natural price, or economic 'fact', stems from the work of one particular group of welfare economists writing in the mid to late 1990s, and who explicitly brought the methods of welfare economics to bear on the problems presented by markets in transplant organs. These economists wished to demonstrate the social welfare benefits that might flow from the legalisation of markets for organs. In the absence of legally available price data they needed to hypothesise and model the likely supply and demand curves for a market. In this case, the demand schedule appeared to be straightforward: with transplant operations a cheap alternative to prolonged dialysis, analysts may reasonably assume that insurers and health services will continue to fund the purchase of an organ, irrespective of price fluctuations. In order to establish supply these economists made use of the contingent valuation method (CVM), where individuals are surveyed and asked their willingness to pay (WTP) to obtain a good and willingness to accept (WTA) to forfeit the good. The supply curve may be statistically derived from their answers. Adams et al. (1999) are the first to hazard an estimate of the incentive needed secure a contract for future donation. They conduct a survey of students at Auburn University to establish the WTP and WTA for a posthumous donation; their results indicate that supply would be very responsive to incentives, with a price of $\$ 1,000$ per donor clearing the market (Adams, Barnett \& Kaserman, 1999: 154), and leading a 'relatively trivial' price per organ. This equilibrium price is inferred from the modelled supply schedule on the basis of donation levels in 1996.

The words 'statistically derived' hide much, however, and researchers who wish to pay attention to the complex arrangements that surround the birth of a fact need to linger over Adams et al.'s method a moment longer. The CVM is popular among environmental economists who cannot empirically access prices for the goods in which they are interested. It has been useful in attempting to model the demand schedule for clean air (Wellington \& 
Whitmire, 2007) and also features in high-stakes legal proceedings, for example when firms are prosecuted for environmental damage (Portney, 1994). It is based upon the assumption that an individual may derive 'utility' from the existence of something, such as a natural landscape, without ever seeing or using that thing. Moreover, it assumes that the appropriate method of valuing any 'utility' is an economic one: the survey respondent is constituted as an individual agent and is asked to express a set of preferences through the dispersal of an imaginary budget. The respondent is then assumed to be maximising and representative of the relevant group (Mitchell \& Carson, 1989). It is therefore explicitly performative in the sense that it imposes an economic mode of valuation upon participants and attempts to reduce a range of concerns to a price function.

Economists recognise that contingent valuation methodologies are problematic in terms of their ability to inform policy (Portney, 1994). Respondents tend to overspend, splashing hypothetical money on hypothetical goods, and WTP estimates remain high (Diamond \& Hausman, 1994; Park \& MacLachlan, 2008). For other goods, particularly public goods with 'degenerate' utility functions, WTA values tend to be much higher than WTP values, as individuals take a stance against the property rights implied by the survey method (Mitchell \& Carson, 1989). Discrepancies between WTP and WTA value are recognized as more than methodological artefacts; there are deeper issues hidden within the calculations as economists struggle to purify social relationships and nonmarket factors from prices. In this particular case, there is an asymmetry of permission at the centre of Adams et al.'s survey. While students were asked the smallest amount they would be willing to accept to grant permission to have their (or a relative's) organs harvested at death, they were asked the largest amount they would be willing to pay to prevent their organs from being removed, 'assuming that an organ procurement organisation had the right to collect their organs without permission and 
in the absence of such a pre-death agreement' (p.152, my italics). Respondents were being polled not only on their attitudes to organ donation, but also implicitly surveyed on their views on self-ownership and bodily integrity; it is easy to imagine that the most enthusiastic organ donor might balk at the prospect of forced retrieval without permission. High WTA estimates have been linked to 'protest' answers to surveys, and it is plausible here that respondents' resistance to a perceived violation of bodily integrity might lead to a similar outcome in WTP values.

For a class of Auburn sophomores, the exercise of pricing their own demise must have been particularly hypothetical. The problems with WTP become apparent in another, methodologically identical, CVM calculation (Wellington \& Whitmire, 2007), which suggests that the equilibrium price of cadaveric kidneys would be prohibitively high. Wellington and Whitmire are concerned that the survey methods used by Adams et al. were inadequate in terms of the reliance on undergraduates as a survey sample, and due to the possibility of anchoring bias (Tversky \& Kahneman, 1974), where a limited range of values on the survey instrument forced WTP and WTA estimates downwards. Their study replicates Adams et al.'s survey, but collects responses from a broader and older population. Their results show a slower uptake at the same incentive levels than do Adams et al. so that an incentive of $\$ 100$ produces a national supply of 12,378 kidneys for Adams et al. and just 8,963 for Wellington and Whitmire. In itself, this is an important finding, as Adams et al. have made much of the price responsiveness of organ donation; in the second survey, every dollar has much less purchasing power and prices are higher. But the most important finding of Wellington and Whitmire's study is to show the sensitivity of any proposed equilibrium price to changes in underlying data: the recalculated equilibrium value in 2003 was $\$ 1.2$ trillion. Compare Adams et al.'s \$280 (sic: two hundred and eighty dollars!); if live donors 
(unpaid) were incorporated the equilibrium prices are $\$ 144,216$ and $\$ 18$. The clearing price was so high, Wellington and Whitmire reveal, because the WTP (the amount that people would pay to avoid forced retrieval after death) did not respond well to financial incentives. Some gave the 'protest' answer of zero: this survey population held clear opinions that financial incentives could do little to shift, and many reject the notion of economic value and exchange in this context. A third, more recent and yet more sophisticated, CVM-based study (Altinanahtar, Crooker \& Kruse, 2008) produces a price range from negative, in the case of high-income 35 year old females who would donate altruistically, to $\$ 1,800$ expected by lowincome 21-year old males. For some members of the population, financial incentives are actually counter-productive. ${ }^{2}$

The natural prices of economists are far from certain, and in these laboratories they can be seen to cling to the circumstances of their production. Yet they still manage to exert enormous technical power over competing moral claims, and so Wellington and Whitmire argue that their study has a twin purpose: not only to demonstrate the importance of appropriate data and survey instruments, but also to make a political argument for the inclusion of non-incentivised live donors in incentive systems. Not at any point do these arguments stop to consider the complexity of decisions that are being reduced into the proxies of WTP and WTA, nor indeed the issues of incentive-driven cadaveric procurement sitting alongside a live donation system. Instead, the writers concentrate on the technical problems relating to data selection and treatment and philosophical questions become explicitly empirical.

\footnotetext{
${ }^{2}$ On this point, economic modelling corroborates classic anthropology (Titmuss, 1970; Healy, 2006)
} 
Altinanahtar and colleagues also draw our attention to a serious problem not tackled in the original paper. Contracts for the posthumous use of organs effectively create a futures market, where the crucial factor is usability: only those individuals who die suddenly and before their time, often through accident, become high quality donors, while a further group may provide lower-quality, extended criteria donors. ${ }^{3}$ If $6 \%$ of all deaths result in a usable cadaver, then donation will satisfy market need. At $3 \%$ usability, the cost of contracts will be $\$ 4,000$, while below $3 \%$ usability there is inelasticity in supply from cadavers and the market cannot be satisfied. There are, in other words, factors beyond the control of supply and demand curves. The actual physical supply of cadaveric organs through appropriate and often untimely deaths might have the consequence of rendering a market unworkable: it is when the economic arrangement established by prices 'leaves its sheltered laboratory existence for the world...that formerly confined uncertainties begin to overflow' (Tryggestad, 2005:605)

Methodological issues apart, Adams et al.'s demonstration that the prices of cadaveric donation are trivial sets the tone for subsequent debate. It is probably helpful that the valuation arrived at is a round number: $\$ 1000$. Once established, this $\$ 1000$ quantitative artefact (in the sense that it is replicable only in the local conditions of Adams et al.'s experimental setting) slips its chains and begins to travel. As a 'fact' it becomes of value as a tool in subsequent economic-ethical debate. Sometimes, this is not subtle. It allows Clay and Bock (2002) to proclaim an end to illegal traffic and murder; a well-functioning cadaveric market is held out as a strong ally of those opposed to live vending, as the trivial rewards available will deter vendors (Kaserman, 2005). But the existence of an economic fact allows aspects of the debate that would otherwise elude economists to be dragged into the realm of

\footnotetext{
${ }^{3}$ I ignore the ethical ramifications of a futures market in human organs.
} 
economic valuation. For example, in a dispute between Emmanuel Thorne and the Barnet/Kaserman (BK) group, the issue of altruism versus sale is debated in purely economic terms: cost versus effectiveness. Thorne (1998), begins by setting the cost of exhortation (i.e. of encouraging new donations) per new organ at $\$ 1,650$, and emphasises the efficiency of exhortation over payment. After many calculative flourishes, BK suggest $\$ 10,102$ as a more appropriate price for exhorting a kidney; ${ }^{4}$ more expensive than the 'trivial' cost of a purchased kidney. The conclusion of this argument is, of course, that we should buy kidneys through a market mechanism; the technical argument has a moral force.

These discussions demonstrate how economic models produce prices that are pure, disentangled (Callon, 1998) from their roots in social settings and moral contexts. And yet, once this is done, the prices immediately assume moral force. Economic models are highly normative; they are performative both in their assembly and in their consequences. The practice of science demands a nesting of proofs and facts, allowing investigators to move forwards on the basis of established knowledge (Latour, 1999b). In the same way, economic facts, once constructed, support further calculative activities, a process shown in the following two examples. The arguments reviewed above have focused on the less-contentious topic of incentivising cadaveric donations, assuming that an adequate potential supply will keep prices down and so preclude live organ vending. But Becker and Elias (2007) produce a highly calculative argument in favour of live organ vending as a means of ameliorating the current waiting lists for kidney and liver transplants. Despite a significant change in the range and content of ethical arguments opened up by a sudden switch from cadaveric to live organ vending, Becker and Elias devote their efforts to developing a new and even more sophisticated means of setting a price on transplant organs.

\footnotetext{
${ }^{4}$ The alert reader will have noticed an increasing specificity of estimation on the part of these writers: $\$ 1000$, $\$ 1,650$, and finally $\$ 10,102$.
} 
Becker and Elias' calculation assumes that the 'reservation price of an organ has three main additive components: a monetary compensation for the risk of death, a monetary compensation for the time lost during recovery, and a monetary compensation for the risk of reduced quality of life' (Becker \& Elias, 2007:9). The last of these proves difficult to assess, and is accorded a 'generous' (i.e. arbitrary) $\$ 7,500$ value. The second is calculated on the basis of a month's lost earnings for an individual earning $\$ 35,000$. The first component, compensation for a risk depends on a particular set of calculations known as the "value of statistical life' (VSL), pioneered by Mishan (1971): the 'money premium required to bear a small increase in the probability of death...estimated empirically in many studies from risky market activities that involve trade-offs between money and fatality risks' (Becker \& Elias, 2007:10). ${ }^{5}$ On the basis of these calculations, Becker and Elias estimate that a sum of $\$ 15,200$ would elicit sufficient donations from US residents to clear the market. Liver donation is a more risky procedure, with a longer lay-off and a larger quality of life impact: the necessary incentive per liver would therefore be $\$ 37,600 .^{6}$

Becker and Elias' calculations are not constructed from the ground up, but make use of calculative methods already well-established in health economics, using risk premia expressed by the VSL. The VSL does not need to be unpacked, examined, or recalculated, but simply forms one of the foundations for an exercise in moral economics. It is also noticeable that the sophistication of the methods in some parts of the calculation hides

\footnotetext{
${ }^{5}$ Symmetrically, 'an individual's 'value of statistical life (VSL) is her marginal rate of substitution between survival probability and wealth - the rate at which she is willing to make exchanges between monetary wealth and small changes in survival probability. For example, someone who would pay $\$ 1,000$ to eliminate a one-time fatality risk of 0.0001 would have a value of statistical life of approximately $\$ 1,000 / 0.0001=\$ 10 \mathrm{~m}$ ' (Bergstrom, Garratt \& Sheehan-Connor, 2009:1316).

${ }^{6}$ If these prices seem low, it is worth remembering that in the case of analyses based on risk premia, for example for dangerous work, prices are determined by the most risk friendly or economically disadvantaged members of the populace (Kelman, 1981).
} 
arbitrary decisions taken in others: the generous compensation for a reduced quality of life, and the choice of $\$ 35,000$ as the income level against which compensation for lost earnings should be gauged. The calculations might look quite different had they been based upon the salary and expectations of leading economics professors! Nor, indeed, are we alerted to the many controversies inherent in the reductive nature of the VSL and its many assumptions about the commensurability of risk, money and human life (Fourcade, 2009). As with the CVM described above, the analysts have gone to great lengths to establish a market price for an organ that purges it of ethical and social issues in order to organise a debate on economic lines.

Both the CVM and Becker and Elias' calculation are abstractions, designed to simulate prices in the absence of their practical context. Another approach might be to integrate the calculations within the existing infrastructure of healthcare economics in the field. Such a method, exemplified by Matas and Schnitzler (2004), falls within the project of 'economists as engineers' (Roth, 2002), relying on algorithms and game theoretic reasoning rather than abstractions of supply and demand. Matas and Schnitzler examine the cost savings that a transplant might bring about and so establish the maximum that a buyer might pay. Dialysis is more expensive than a transplant and substituting one for the other saves $\$ 94,579$ over a 20 year period, in addition to which a quality of life adjustment drives the total cost-saving to $\$ 269,319$. As all donors would have to be paid, the payment per donor would vary, and would depend also on the size of the eventual pool accumulated: Matas and Schnitzler eventually settle on a societal break even figure of $\$ 90,000$ per donor.

Matas and Schnitzler's argument is more interesting for its calculative apparatus than its eventual valuation of a kidney. The transplant/dialysis question is understood as a process 
with five outcomes and a return loop from cases of graft failure to the waiting list. The process is modelled with factors including 'patient survival, cost on dialysis, graft survival, death with function, death after graft loss, cost of organ acquisition, cost of transplant, maintenance costs with graft function and cost of return to dialysis' (Matas \& Schnitzler, 2004). Like the other calculations discussed, this model makes use of existing measures; unlike those calculations, the measures used are already operational in medical organisations. Some, such as measures of graft survival probabilities of death are statistically derived from historical records. Others, such as cost of acquisition of the organ transplant, reflect the systems of costings and payments that necessarily exists in the bureaucratic organisation of health services. In the highly marketized healthcare system of the US, where Matas and Schnitzler are writing, organ procurement organisations are able to recoup acceptable expenses and an entrepreneurial industry of procurement has sprung up (Anteby, 2009) with cadavers accruing economic surplus as they travel from donor to eventual recipients in scientific laboratories and operating theatres (Healy, 2006). In national health services such as the United Kingdom's NHS, internal markets are harder to discern yet equally ubiquitous: surgeons in well-equipped central hospitals must bid for surgery time and resources on the basis of expected returns from those local health authorities whose patients are treated.

The problems of allocation of resources, and of commensurability, are exemplified by the Quality Adjusted Life Year (QALY), a standard measure central to Matas and Schnitzler's argument. The QALY is a standardised and widely adopted measure that allows healthcare professionals to allocate resources appropriately (Phillips, 2009). Not only does the costutility score allow administrators to ascertain the relative efficiency of treatments relating to similar conditions; it also allows administrators to allocate resources between otherwise incommensurate medical conditions on the basis of cost-utility (Mortimer \& Segal, 2008). 
The wide use and the implications of the QALY as a performative market device have already been recognised (Sjögren \& Helgesson, 2007). Matas and Schnitzler assume that the QALY for transplants is the same as for dialysis, and thus calculate the long term opportunity cost of dialysis. A transplant organ, they suggest, is worth both the present and future cost savings that it generates; in making this claim, Matas and Schnitzler's argument extends an existing instrumental managerial discourse of cost efficiency to its conclusion. Economics is seen here, not as a hypothetical modelling of market processes, but a genuine extension of existing managerial practice.

This section has considered three differing sets of calculations presented in economic and medical journals, all of which seek to justify the implementation of market-based systems for the procurement of organs for transplantation. In each instance, the arguments hypothesise a system of organisation that has been entirely subjugated to economic modes of valuation, and operate within this to produce valuations according to economic methodologies. These valuations may then be used as the basis of discussions as to the validity of a given system of organisation. Where this point is not made explicitly, and the calculations are presented as a simple exercise in the positive economics of human behaviour, it remains a small step to move from an instrumental to a normative set of arguments. I have shown throughout this section how such a step might be made, with economic simulations containing implicit moral claims based on the economic virtues of cost efficiency and social welfare.

\section{Discussion: performing value}

In this way, a collection of economists, surgeons and economically minded philosophers have attempted to impose a regime of economic value on the current arrangements for supplying 
organs for transplantation. M theoretical framework for discussion is Callon's (1998) 'performativity thesis', the claim that economics actively constitutes and bounds the economy. Callon proposes an anthropology of valuation, investigating the economic configuration of individual calculative agencies and the setting of the boundaries of the economic (Callon, 2008; Çalışkan \& Callon, 2010). I propose that 'contested' markets are particularly rich areas to investigate, emphasising the normative content of economic evaluations and giving a glimpse into an economic laboratory as yet uncontaminated by 'the wild'.

In the examples discussed, the rhetorical force and linguistic power of economics (McCloskey, 1986) are most apparent. The very possibility that a debate over transplant organs can take place in economic language is itself performative, taking the argument from a terrain populated by discourses of moral obligation and worth into one arranged by a particular set of economic values. Economic values are parsimoniously expressed as numbers: expressions of preference contained in price. While economists have engaged with the ethical debate in superficial ways, in their accounts the real work of ethical reasoning is done by economic calculation and quantification. In this, economics has the support of philosophy; as Cherry (2005) notes, the real test of autonomist ethics comes in the calculation of benefits. Health economic measures such as the QALY may contain some notion of the good life, but this is philosophically unsophisticated at best (Brock, 2001). Yet economics has provided a sophisticated technocratic discourse that has allowed a moral sphere to be analysed and discussed in a particular way. Laboratory interventions develop 'natural prices', such as the $\$ 1000$ cadaver, which travel and colonize future debates. As Tryggestad (2005) notes, natural prices are powerful actors, transforming other actors into docile servants. Those who do not organize their activities on economic lines - surgeons and healthcare 
professionals, who may have other practical or ethical agendas, are accused of rent-seeking (Barnett, Beard \& Kaserman, 1993).

As Bauman (1989) argues, the replacement of moral with technocratic responsibility is a sleight of hand characteristic of modern organisations; the rational organ vendor seems a long way from the individuals upon whom ethicists and anthropologists focus, driven by altruism, love or economic desperation to surrender part of themselves for an organ transplant. Costsavings analyses and demand side calculations bear little resemblance to the everyday activities of surgeons, discerning consumers who discard one of every two transplant organs that pass through their hands (Howard, 2002). The key authors in the debate, experts in antitrust, regulation and microeconomic policy, view these complex issues in terms of inefficiency, waste, and market distortion (Kaserman \& Barnett, 1991). Just as philosophical arguments need to be answered in philosophical terms - rights, autonomy and the goods of life - so calculative economic reasoning may only be countered by more calculation. An economised moral argument must be heard on economic grounds, governed by the goods of economics: efficiency, social welfare, liquidity and transparency. As we have also seen demonstrated by the wide range of prices and values conjectured, 'all the mathematical sophistication and rigour that may go into the modes of computation may be undermined by the arbitrariness of the choices to adopt one principle for quantifying rather than another' (MacIntyre, 1992 :186), a phenomenon that appears to go unrecognized by the analysts themselves. Yet even among enthusiasts for a market, methodology may not be everything; the elegantly constructed prices offered by Becker and Elias do not seem to have achieved such autonomy as the thousand dollar cadaver. 
Echoing Steiner (2011), I propose that the topic of markets for transplant organs provides an important site for the study of economic performativity. It is the task of researchers investigating this site to unravel and document the interactions between economic theory and the world through which social and organizational structures are performed (Holm \& Nielsen, 2007). Methodologically, these interactions must be sought through a close study of the calculative techniques and discourses called into play. This paper has documented some of these techniques. As economists have attempted to explore the functioning of these hypothetical markets we have seen calculative tools of great sophistication deployed to ascertain the monetary value of medical treatments, of years of life, and of the transplant organs themselves. In the first two cases we saw a process of 'purification' (Tryggestad, 2005) where laboratory methods were employed to produce 'natural' prices, free from the messy constraints of bodies, relationships, and social norms. Calculations are underpinned by the assumption of instrumentally maximising rationality in vending or donating individuals; as Bergstrom et al. pithily put it, 'a rational potential donor whose choices are consistent with a von Neumann-Morgenstern utility function' (Bergstrom, Garratt \& Sheehan-Connor, 2009:1323). The very methods that are used to generate such prices are performative in their own right, demanding that respondents act as economic agents in situations where instrumental rationality may not necessarily occur. At the same time, it is possible to discern in the inelasticity of the supply curve a resistance to economic incentives; as models strive to frame and purify the economic decision, they generate resistance and moral quandary. As Callon (1998) makes clear, economic frames are persistently unstable and overflowing. Actors may deploy the very tools that economists have forced on them, offering prices that protest against the economic norms implicit in, for example, survey prices. A reframing, and further purification, requires all direct participation to be removed, replaced instead by the preferences inferred by Becker and Elias (2007) from national datasets. Cultural studies of 
economization, such as Zelizer's work on insurance (2005), have shown that cultural discourses themselves shape practices as economic. In the case of organ transplantation, debates among academics and professionals strive to establish the norms of economic agency. A performativity-inspired analysis must move beyond culture and language to focus on the technical minutiae of economic life, for as I have shown, language itself is reflexively bound up with the material models and methods that bring economic practices into being.

The moral consequences of performativity are important. Callon (1998) emphasises the ability of markets to disentangle social relationships and leave both parties in a transaction satisfied and uncommitted. An altruism-based live liver transplant program running in Scotland had resulted in just one transplant in the course of 18 months: the recipients, it seems, considered the procedure too dangerous for their spouses and siblings to undergo ${ }^{7}$. Recasting such a decision to a structured and uncommitted market exchange runs the risk of obliterating the distinction between manipulative and non-manipulative social relations (MacIntyre, 1981) at the very time when such distinctions are most needed. In giving us an understanding of the socially constitutive role of economics, the performativity thesis allows us to ask the question: what kind of world would we like to inhabit? Some twenty years after the original paper by Adams et al., the debate remains current. In 2011, the Nuffield Council for Bioethics published its consultation on human bodies in research, a discussion of the legitimacy of using incentives to increase supply of transplant organs, the efficacy of such measures considered beyond discussion. ${ }^{8} \mathrm{~A}$ persistent focus on incentives and supply obscures the social and political questions that stand behind ballooning waiting lists: problems of diet and obesity, the distribution of wealth in contemporary society, and the ethical issues concerning the use of advanced surgical techniques as routine treatment.

\footnotetext{
${ }^{7}$ Seminar: Ronan O'Carroll, Social Dimensions of Health Institute, Dundee University, 4 February 2011

${ }^{8}$ Nuffield Council on Bioethics (2011) Human Bodies: Donation for Medicine and Research, London
} 
It remains to indicate where future research may usefully be directed. This article has argued that the language and models of economics are powerful enough to contest, or even change, the shape of public discourse over transplantation. It is imperative to extend the study to the pragmatics of the retrieval and allocation of transplant organs. The relationship between economic theory and everyday practice is far from straightforward in any area, and is especially complex in medicine. Economics' laboratory-made constructions of price come under pressure when released into the wild. In the case of transplant organs we know that much of the infrastructure for a calculative and utilitarian approach to organ retrieval and allocation is already in place. The economic surplus accrued by a cadaver during the transplantation process has an unavoidable impact on the organizations that handle it (Anteby, 2009). In the United States, increasing numbers of hospitals have set up transplant units in order to avoid sending their retrieved organs elsewhere and to capture their share of a lucrative market (Mahoney, 2000:185). Advanced surgery is expensive and resource intensive, and as my analysis notes, quantitative infrastructures are important determinants of the availability of treatment. Meanwhile sociological and ethnographic studies of organ collection show an activity rich in meaning and symbolism (Sharp, 2006). There is, therefore, a need for qualitative research with a specific focus on the impact of the calculative apparatus of economics on surgical practice in this area. A research project inspired by a material sociology would base this examination on the micro-level processes of calculation: algorithms and procedures, and their impact on day to day medical practice. It should also investigate the relationship between accounting practices and organizational arrangements in the transplant sector, as accounting offers stability and visibility to economic modes of valuation. 
Transplantation is a technique at the forefront of medical science, enabling surgeons to give the very sickest a new lease of life. Because of this, it is necessarily at the forefront of medical ethics also, presenting us with questions that we could barely have imagined 50 years previously. While just a part of the broader spectrum of moral issues that transplantation entails, the role of economics remains important and is likely to be of vital area of study for scholars of markets in coming years. 


\section{Bibliography}

Adams, A., Barnett, A., \& Kaserman, D. (1999) 'Markets for organs: The question of supply,' Contemporary Economic Policy, vol. 7, pp. 147-55.

Altinanahtar, A., Crooker, J.R., \& Kruse, J.B. (2008) 'Valuing human organs: An application of contingent valuation,' International Journal of Social Economics, vol. 35, no. 1/2, pp. 5-14.

Anteby, M. (2009) 'A market for human cadavers in all but name?', Economic Sociology, European Electronic Newsletter, vol. 11, no. 1, pp. 3-7.

Austin, J. (1978) How to do Things with Words, Oxford, Oxford University Press.

Barnett, A.H., Beard, T.R., \& Kaserman, D.L. (1993) 'The medical community's opposition to organ markets: Ethics or economics?', Review of Industrial Organization, vol. 8, no. 6 , pp. $669-78$.

Barnett, W., Saliba, M., \& Walker, D. (2001) 'A free market in kidneys: Efficient and equitable,' The Independent Review, vol. V, no. 3, pp. 373-85.

Bauman, Z. (1989) Modernity and the Holocaust, Cambridge, Polity Press.

Becker, G., \& Elias, J.J. (2007) 'Introducing incentives in the market for live and cadaveric organ donations,' Journal of Economic Perspectives, vol. 21, no. 3, pp. 3-24.

Becker, G.S. (1973) 'A theory of marriage: Part I,' Journal of Political Economy, vol. 81, no. 4, pp. 813.

Bergstrom, T.C., Garratt, R.J., \& Sheehan-Connor, D. (2009) 'One chance in a million: Altruism and the bone marrow registry,' American Economic Review, vol. 99, no. 4, pp. 1309-34. 
Blaug, M. (1984) 'Paradigms versus research programmes in the history of economics', The Philosophy of Economics, edited by Hausman, D., Cambridge, Cambridge University Press pp. 360-89.

Bowker, G.C., \& Leigh Starr, S. (1999) Sorting things out, Cambridge, Massachusetts, MIT Press.

Brock, D. (2001) 'Quality of life measures in healthcare and medical ethics', Bioethics, edited by Harris, J., Oxford, Oxford University Press pp. 387-426.

Çalışkan, K., \& Callon, M. (2009) 'Economization, part 1: Shifting attention from the economy towards processes of economization,' Economy and Society, vol. 38, no. 3, pp. $369-98$.

Çalışkan, K., \& Callon, M. (2010) 'Economization, part 2: A research programme for the study of markets,' Economy and Society, vol. 39, no. 1, pp. 1 - 32.

Callon, M. (1998) 'The embeddedness of economic markets in economics', The Laws of the Markets, edited by Callon, M., Oxford, Oxford University Press, pp. 1-58.

Callon, M. (2008) 'Economic markets and the rise of interactive agencements', Living in a Material World, edited by Pinch, T. \& Swedberg, R., Cambridge, Massachusetts, The MIT Press, pp. 29-56.

Cherry, M.J. (2005) Kidney for Sale by Owner, Washington DC, Georgetown University Press.

Clay, M., \& Bock, W. (2002) 'A free market for human organs,' The Journal of Social, Political and Economic Studies vol. 27, no. 2, pp. 227-33.

Cochoy, F., Giraudeau, M., \& McFall, L. (2010) 'Performativity, economics and politics,' Journal of Cultural Economy, vol. 3, no. 2, pp. 139-46.

Diamond, P.A., \& Hausman, J.A. (1994) 'Contingent valuation: Is some number better than no number?', The Journal of Economic Perspectives, vol. 8, no. 4, pp. 45-64. 
Dworkin, G. (1994) 'Markets and morals: The case for organ sales', Morality, Harm, and the Law, edited by Dworkin, G., Boulder, Colorado, Westview Presspp. 155-61.

Ferraro, F., Pfeffer, J., \& Sutton, R.I. (2005) 'Economic language and assumptions: How theories can become self-fulfilling,' Academy of Management Review, vol. 30, no. 1, pp. 8-24.

Fourcade, M. (2009) 'The political valuation of life,' Regulation and Governance, vol. 3, no., pp. 291-97.

Friedman, M. (1966) 'The methodology of positive economics', Essays on Positive Economics, Chicago, University of Chicago Press.

Healy, K. (2006) Last Best Gifts: Altruism and the Market for Human Blood and Organs, Chicago, University of Chicago Press.

Holm, P., \& Nielsen, K.N. (2007) 'Framing fish, making markets: The construction of individual transferable quotas (ITQs)', Market Devices, edited by Callon, M., Millo, Y., \& Munesia, F., Oxford, Blackwell Publishing/ The Sociological Review, pp. 17395.

Howard, D.H. (2002) 'Why do transplant surgeons turn down organs?: A model of the accept/reject decision,' Journal of Health Economics, vol. 21, no. 6, pp. 957-69.

Kaserman, D. (2005) "'Should we sell human organs?" Correction of a faulty analysis,' International Journal of Social Economics, vol. 32, no. 10, pp. 893-98.

Kaserman, D., \& Barnett, A. (1991) 'An economic analysis of transplant organs: A comment and extension,' Atlantic Economic Journal, vol. 19, no. 2, pp. 57-63.

Kelman, S. (1981) 'Cost benefit analysis: An ethical critique,' Regulation, vol. 10, no., pp. $33-40$.

Latour, B. (1988) The Pasteurization of France, Cambridge, Massachusetts, Harvard University Press. 
Latour, B. (1999a) 'On recalling ANT', Actor Network Theory and After, edited by Law, J. \& Hassard, J., Oxford, Blackwell, pp. 15-25.

Latour, B. (1999b) Pandora's Hope, Cambridge, Massachusetts, Harvard University Press.

Licoppe, C. (2010) 'The 'performative turn' in science and technology studies,' Journal of Cultural Economy, vol. 3, no. 2, pp. 181-88.

MacIntyre, A. (1981) After Virtue: A Study in Moral Theory, London, Duckworth.

MacIntyre, A. (1992 ) 'Utilitarianism and cost benefit analysis: An essay on the relevance of moral philosophy to bureaucratic theory ', The Moral Dimensions of Public Policy choice, edited by Gillroy, J. M. \& Wade, M., University of Pittsburgh Press, Pittsburgh, pp. 179-94.

MacKenzie, D. (2006) An Engine, not a Camera: How Financial Models Shape Markets, Cambridge, MIT Press.

MacKenzie, D. (2009) Material Markets: How Economic Agents are Constructed, Oxford, Oxford University Press.

MacKenzie, D., \& Millo, Y. (2003) 'Constructing a market, performing theory: The historical sociology of a financial derivatives exchange,' American Journal of Sociology, vol. 109, no. 1, pp. 107-45.

Mahoney, J.D. (2000) 'The market for human tissue,' Virginia Law Review, vol. 86, no. 2, pp. 163-223.

Matas, A.J., \& Schnitzler, M. (2004) 'Payment for living donor (vendor) kidneys: A costeffectiveness analysis,' American Journal of Transplantation, vol. 24, no. 2, pp. 21621.

McCloskey, D. (1986) The Rhetoric of Economics, Brighton, Wheatsheaf Books

Mishan, E.J. (1971) 'Evaluation of life and limb: A theoretical approach,' The Journal of Political Economy, vol. 79, no. 4, pp. 687-705. 
Mitchell, R.C., \& Carson, R. (1989) Using Surveys to Value Public Goods: The Contingent Valuation Method, Washinton DC, Resources for the Future.

Mortimer, D., \&Segal, L. (2008) 'Comparing the incomparable? A systematic review of competing techniques for converting descriptive measures of health status into QALY-weights,' Medical Decision Making, vol. 28, no. 1, pp. 66-89.

Park, J.H., \& MacLachlan, D.L. (2008) 'Estimating willingness to pay with exaggeration bias-corrected contingent valuation method,' Marketing Science, vol. 27, no. 4, pp. 691-98.

Phillips, C. 2009. "What is a QALY?" in What is...?, London, Hayward Publishing Group.

Portney, P.R. (1994) 'The contingent valuation debate: Why economists should care,' The Journal of Economic Perspectives, vol. 8, no. 4, pp. 3-17.

Roth, A.E. (2002) 'The economist as engineer: Game theory, experimentation, and computation as tools for design economics,' Econometrica, vol. 70, no. 4, pp. 134178.

Roth, A.E. (2007) 'Repugnance as a constraint on markets,' Journal of Economic Perspectives, vol. 21, no. 3, pp. 37-58.

Roth, A.E., Sönmez, T., \& Ünver, M.U. (2005) 'A kidney exchange clearing house in New England,' American Economic Review, vol. 95, no. 2, pp. 376-80.

Scheper-Hughes, N. (2003) 'Keeping an eye on the global traffic in human organs,' The Lancet, vol. 361, no. 9369, pp. 1645-48.

Sharp, L.A. (2006) Strange Harvest, Berkeley, University of California Press.

Sjögren, E., \& Helgesson, C. (2007) 'The Q(u)ALYfying hand: Health economics and medicine in the shaping of swedish markets for subsidized pharmaceuticals', Market Devices, edited by Callon, M., Millo, Y., \& Muniesa, F., Oxford, Blackwell, pp. 21541. 
Steiner, P. (2010) 'Gift-giving or market,' Journal of Cultural Economy, vol. 3, no. 2, pp. 243-59.

Taylor, J. (2005) Stakes and Kidneys, Aldershot, Hants, Ashgate Publishing Company.

Thorne, E.D. (1998) 'The shortage in market-inalienable human organs: A consideration of "nonmarket" failures,' American Journal of Economics and Sociology, vol. 57, no. 3, pp. 247-60.

Titmuss, R. (1970) The Gift Relationship : From Human Blood to Social Policy, London, Allen \& Unwin.

Tryggestad, K. (2005) 'Natural and political markets: Organizing the transfer of technology and knowledge,' Economy and Society, vol. 34, no. 4, pp. 589-611.

Tversky, D., \& Kahneman, A. (1974) 'Judgement under uncertainty,'Science, vol. 185, pp. 1124-31.

Wellington, A.J., \& Whitmire, J.B. (2007) 'Kidney transplants and the shortage of donors: Is a market the answer?,' Contemporary Economic Policy, vol. 25, no. 2, pp. 131-45.

Zelizer, V.A. (1979) Morals and Markets: The Development of Life Insurance in the United States, New York, Columbia University Press.

Zelizer, V.A. (2005) The Purchase of Intimacy, Princeton, Princeton Univerity Press. 